\title{
PERANCANGAN DAN VALIDASI ALAT PENGUKURAN KONSTANTA DISOSIASI ASAM PADA SUHU 30-70 ${ }^{\circ} \mathrm{C}$
}

\author{
Vitro Rahmat ${ }^{1}$, Desi Kurniawan ${ }^{2}$, Sholeh Ma'mun ${ }^{3}$ \\ Jurusan Teknik Kimia, Fakultas Teknologi Industri, Universitas Islam Indonesia ${ }^{1,2,3)}$ \\ Jl. Kaliurang Km. 14,5 Yogyakarta 55584 \\ E-mail:sholeh.mamun@uii.ac.id ${ }^{3}$
}

\begin{abstract}
The greenhouse effect is caused by increasing emissions of greenhouse gases, e.g. carbon dioxide, in the atmosphere leading to the global warming problem. Thus necessary efforts to reduce the $\mathrm{CO}_{2}$ emissions are required, e.g. amine-based absorption method. Protonation constant is required for the VLE modeling needed in designing absorber and desorber column. For this purpose, an experimental setup was designed to measure alkanolamine protonation constants $\left(p K_{a}\right)$. However, the setup needs to be validated by measuring the protonation constants of acetic acid at a range of temperatures from 30 to $70^{\circ} \mathrm{C}$. The validation results obtained were in good agreement with the literature data. For example, the $p K_{a}$ of the acetic acid at $30^{\circ} \mathrm{C}$ is 4.751 and this gives a deviation of $0.18 \%$ from the literature data.
\end{abstract}

Keywords : Greenhouse Effect; Carbon Dioxide; Absorption; Protonation Constant; Acetic Acid.

\section{PENDAHULUAN}

Temperatur global rata - rata pada permukaan Bumi telah meningkat $0,74 \pm$ $0,18^{\circ} \mathrm{C}$ selama seratus tahun terakhir. Intergovernmental Panel on Climate Change (IPCC) menyimpulkan bahwa sebagian besar peningkatan suhu global sejak pertengahan abad ke-20 disebabkan oleh meningkatnya konsentrasi gas-gas rumah kaca akibat aktivitas manusia (Alley, R., 2007). Dari gambar 1 terlihat bahwa konsentrasi $\mathrm{CO}_{2}$ di atmosfer relatif konstan sejak 800 ribu tahun lalu hingga sebelum revolusi industri pada tahun 1850-an, yakni sekitar 280 ppm. Saat ini, konsentrasi $\mathrm{CO}_{2}$ di atmosfir sudah mencapai $400 \mathrm{ppm}$. Jadi ada peningkatan konsentrasi $\quad \mathrm{CO}_{2} \quad$ sekitar $\quad 40 \% \quad$ sejak dimulainya revolusi industri.
Kesimpulan dasar ini telah dikemukakan oleh setidaknya 30 badan ilmiah dan akademik, termasuk semua akademi sains nasional dari negara-negara G8. Akan tetapi, masih terdapat beberapa ilmuwan yang tidak setuju dengan beberapa kesimpulan yang dikemukakan IPCC tersebut. Model iklim yang dijadikan acuan oleh proyek IPCC menunjukkan suhu permukaan global akan meningkat $1,1-6,4{ }^{\circ} \mathrm{C}$ antara tahun 1990 dan 2100. Meningkatnya suhu global diperkirakan akan menyebabkan perubahanperubahan yang lain seperti naiknya permukaan air laut, meningkatnya intensitas fenomena cuaca yang ekstrem, dan lain - lain (NASA, Ma'mun, S., Svendsen, H. F, Hoff, K. A., Williams, M). 


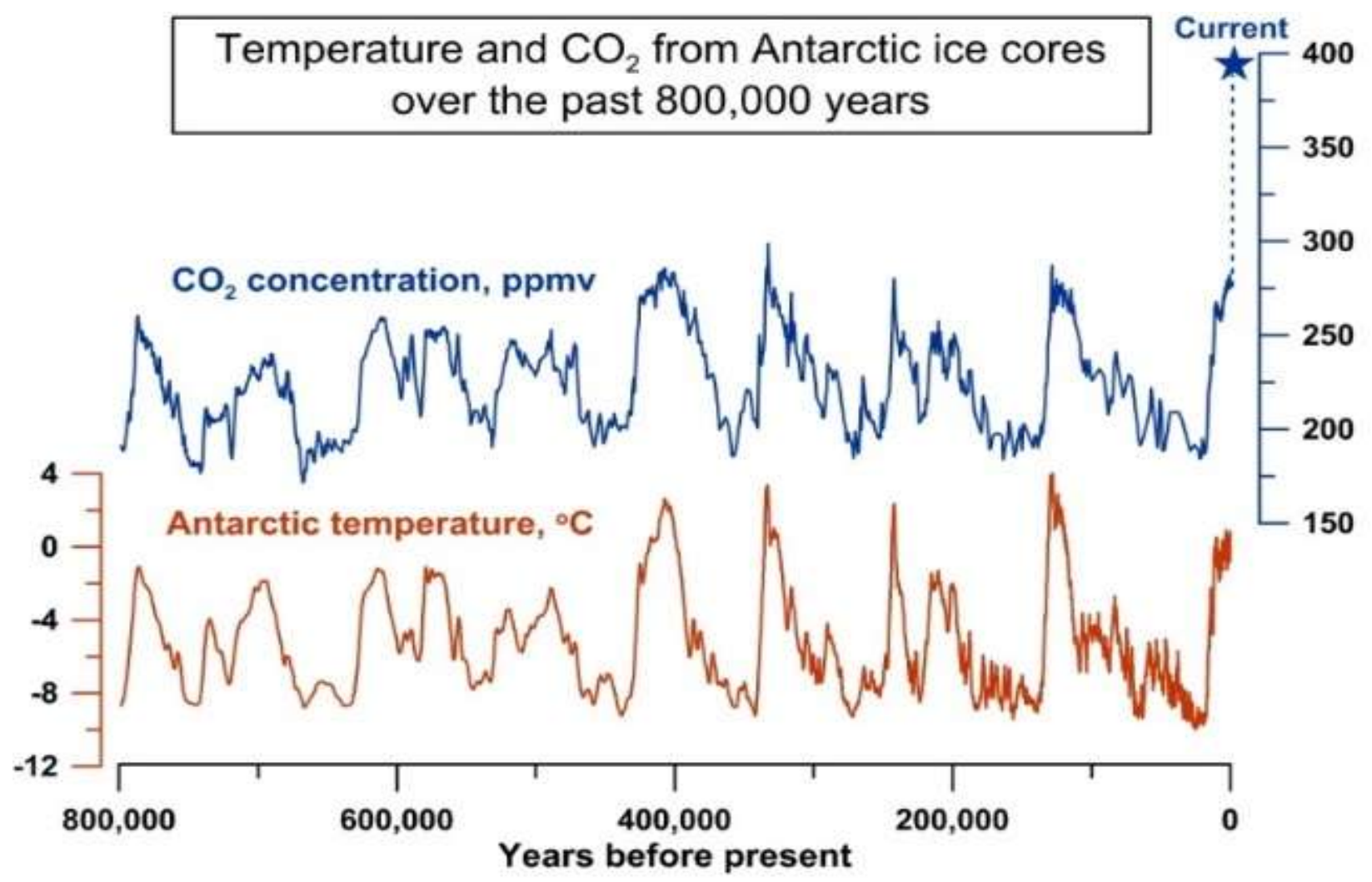

Gambar 1. Konsentrasi $\mathrm{CO}_{2}$ dan Suhu di Antartika.

Konstanta kesetimbangan asam $\left(\mathrm{pK}_{\mathrm{a}}\right)$ merupakan salah satu konstanta yang dibutuhkan dalam pemodelan matematis kesetimbangan uap cair untuk sistem $\mathrm{CO}_{2}$ alkanolamin - air. Sampai saat ini, data konstanta kesetimbangan asam $\left(\mathrm{pK}_{\mathrm{a}}\right)$ untuk larutan alkanolamin yang tersedia di literatur masih sangat terbatas. Untuk itu diperlukan pengukuran konstanta kesetimbangan asam ini untuk beberapa jenis alkanolamin.

Tujuan dari penelitian ini adalah merancang sebuah alat percobaan untuk mengukur konstanta kesetimbangan asam $\left(\mathrm{pK}_{\mathrm{a}}\right)$ pada berbagai suhu. Alat ini kemudian divalidasi dengan mengukur $\mathrm{pK}_{\mathrm{a}}$ untuk asam asetat.

2. METODE PENELITIAN

\subsection{Alat dan Bahan}

Penelitian dilakukan di Laboratorium Penelitian, Program Studi Teknik Kimia, Fakultas Teknik Industri, Universitas Islam Indonesia.

Bahan - bahan yang digunakan antara lain larutan buffer $\mathrm{pH} 4$ dan 7, asam asetat glasial dengan kemurnian $100 \%, \mathrm{NaOH}$, dan aquadest. Rangkaian alat yang digunakan dalam penelitian ini dapat dilihat pada gambar 2 . 


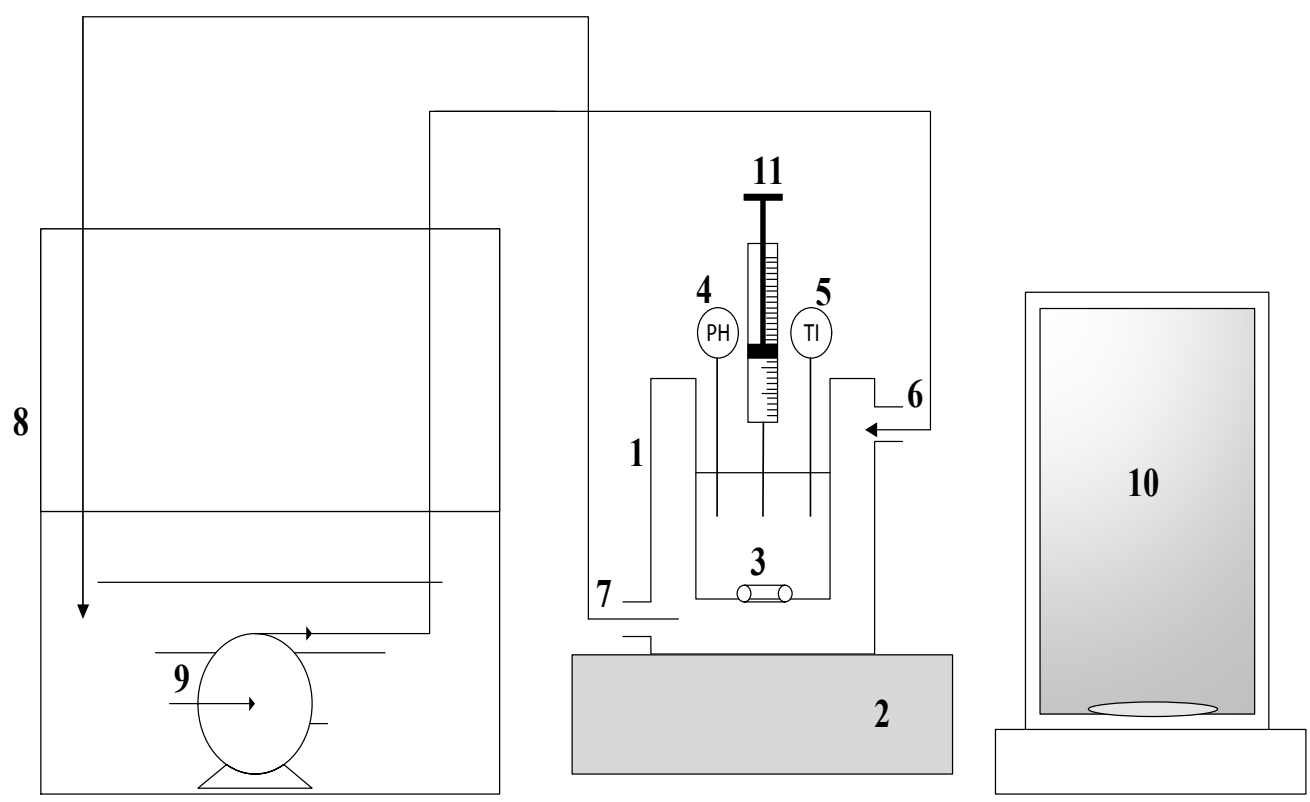

Gambar 2. Rangkaian Alat Percobaan.

\section{Keterangan:}

1. Reaktor Jaket $300 \mathrm{~mL}$.

2. Pengaduk Magnetik.

3. Batang Pengaduk.

4. $\mathrm{pH}$ meter.

5. Termometer Digital.

6. Aliran Panas Masuk.

7. Aliran Panas Keluar.

8. Waterbath.

9. Pompa.

10. Neraca Digital.

11. Syringe $5 \mathrm{~mL}$.

\subsection{Variabel Proses}

Variabel tetap dalam penelitian ini adalah $4 \mathrm{~g} \mathrm{NaOH}$ teknis yang digunakan untuk membuat $\mathrm{NaOH} 0,1 \mathrm{~mol}$ dalam 1000 $\mathrm{mL}$ aquadest, $50 \mathrm{~mL}$ aquadest, dan asam asetat glasial. Variabel bebas yang digunakan dalam penelitian ini adalah variasi titran $\mathrm{NaOH}$ 0,1M yang ditambahkan ke dalam reaktor.

\subsection{Cara Percobaan}

Tahap penelitian diawali dengan membuat alat pengukuran konstanta disosiasi asam (pKa). Alat pengukur konstanta disosiasi asam divalidasi dengan cara pengukuran nilai $\mathrm{pKa}$ asam asetat pada suhu 30-70 ${ }^{\circ} \mathrm{C}$. Alat pemanas dinyalakan sampai suhu yang diinginkan tercapai. Kalibrasi $\mathrm{pH}$ meter dilakukan sebelum penelitian dimulai. Asam asetat glasial sebanyak sekitar $0,5 \mathrm{~g}$ ditambahkan ke dalam reaktor jaket yang sudah berisi aquadest $50 \mathrm{~mL}$. Larutan diaduk sampai homogen.

Selanjutnya ditambahkan sejumlah $\mathrm{mL}$ titran larutan $\mathrm{NaOH} 0,1 \mathrm{M}$ dari syringe yang dilakukan berulang - ulang hingga titik ekuivalen terlampaui. Pada saat mendekati titik ekuivalen, penambahan titran dilakukan dengan jumlah yang sangat sedikit agar titik 
Tabel 1. Data Titrasi Asam Asetat Dengan $\mathrm{NaOH} 0,1 \mathrm{M}$ Pada Suhu $30^{\circ} \mathrm{C}$

\begin{tabular}{c|c|c}
\hline $\mathbf{V}_{\mathbf{N a O H}-\text { tot }} \mathbf{m L}$ & $\mathbf{p H}$ & $\Delta \mathbf{p H} / \Delta \mathbf{V}$ \\
\hline 0 & 3,110 & \\
0,91 & 3,385 & 0,30 \\
1,90 & 3,605 & 0,22 \\
3,60 & 3,85 & 0,14 \\
6,04 & 4,07 & 0,09 \\
10,36 & 4,345 & 0,06 \\
15,52 & 4,59 & 0,05 \\
20,95 & 4,835 & 0,04 \\
24,44 & 4,995 & 0,05 \\
27,37 & 5,155 & 0,05 \\
29,90 & 5,315 & 0,06 \\
33,45 & 5,635 & 0,09 \\
35,98 & 6,08 & 0,18 \\
36,73 & 6,235 & 0,21 \\
37,20 & 6,535 & 0,63 \\
37,64 & 6,945 & 0,94 \\
37,82 & 7,295 & 1,96 \\
37,97 & 8,135 & 5,70 \\
38,16 & 9,585 & 7,30 \\
38,32 & 9,985 & 2,54 \\
38,56 & 10,355 & 1,59 \\
38,98 & 10,755 & 0,94 \\
39,37 & 10,965 & 0,54 \\
39,89 & 11,155 & 0,37 \\
40,75 & 11,335 & 0,21 \\
41,81 & 11,505 & 0,16 \\
44,51 & 11,755 & 0,09 \\
46,21 & 11,855 & 0,06 \\
51,26 & 12.05 & 0,04 \\
\hline
\end{tabular}

ekuivalen tidak terlewati dan perubahan nilai $\mathrm{pH}$ tidak turun secara drastis.

Data - data percobaan yang diukur selama proses berlangsung antara lain volume titran $\mathrm{NaOH}$ yang di tambahkan, $\mathrm{pH}$ larutan asam asetat mula-mula dan setelah titran $\mathrm{NaOH}$ ditambahkan ke dalam reaktor pada setiap suhu percobaan. Pengambilan data dilakukan sebanyak dua kali untuk setiap suhu percobaan.

\section{PEMBAHASAN}

Pada penelitian ini dilakukan perancangan alat pengukur kesetimbangan asam $\left(\mathrm{pK}_{\mathrm{a}}\right)$ yang kemudian dilakukan validasi dengan mengukur $\mathrm{pKa}$ dari asam asetat pada berbagai suhu. Validasi dilakukan dengan penambahan asam asetat glasial dengan jumlah tertentu ke dalam alat percobaan yang telah diisi $50 \mathrm{~mL}$ aquadest, yang kemudian dititrasi dengan $\mathrm{NaOH} 0,1 \mathrm{M}$ 
Tabel 2. pKa Sakam Asetat Pada Berbagai Suhu

\begin{tabular}{c|c|c|c}
\hline $\mathbf{T}\left({ }^{\mathbf{0}} \mathbf{C}\right)$ & $\mathbf{p K}$ percobaan & $\mathbf{p K}_{\mathbf{a}}[\mathbf{5}]$ & Deviasi \\
\hline 30 & 4.751 & 4.759 & $0.18 \%$ \\
\hline 40 & 4.771 & 4.770 & $0.02 \%$ \\
50 & 4.753 & & \\
60 & 4.784 & 4.787 & $0.72 \%$ \\
70 & & 4.811 & $0.55 \%$ \\
\hline
\end{tabular}

dengan jumlah tertentu. Pengukuran dilakukan pada suhu $30-70^{\circ} \mathrm{C}$. Data percobaan yang diperoleh berupa volume $\mathrm{NaOH} 0,1 \mathrm{M}$ yang ditambahkan dan $\mathrm{pH}$ larutan.

Tabel 1 diatas menunjukkan data titrasi asam asetat dengan $\mathrm{NaOH} 0,1 \mathrm{M}$ sebagai titran pada suhu $30^{\circ} \mathrm{C}$. Penambahan titran dilakukan berulang - ulang sampai melampaui titik ekuivalen. Pada saat titrasi berada di sekitar titik ekuivalen, penambahan volume titran harus dilakukan dengan jumlah yang sedikit untuk menghindarai perubahan $\mathrm{pH}$ larutan yang besar.
Hubungan antara volume $\mathrm{NaOH} 0,1 \mathrm{M}$ dengan $\mathrm{pH}$ larutan dapat dilihat pada gambar 3a. Pada saat titrasi berlangsung terjadi reaksi antara asam asetat dan $\mathrm{NaOH}$ sebagai titran dengan persamaan reaksi sebagai berikut :

$$
\mathrm{CH}_{3} \mathrm{COOH}+\mathrm{NaOH} \rightarrow \mathrm{CH}_{3} \mathrm{COONa}+\mathrm{H}_{2} \mathrm{O} \text {...(1) }
$$

Pada proses titrasi untuk mendapatkan titik ekuivalen yang tepat, maka tidak dilakukan penambahan indikator. Titik ekuivalen ditentukan melalui nilai slope $(\Delta \mathrm{pH} / \Delta \mathrm{V})$ yang terbesar. Dari slope terbesar tersebut didapat volume ekuivalen yang kemudian digunakan untuk menentukan nilai $\mathrm{pK}_{\mathrm{a}}$ asam asetat pada variasi suhu yang telah ditentukan. Penentuan $\mathrm{pKa}$ melalui grafis dapat dilihat pada gambar 3 . 

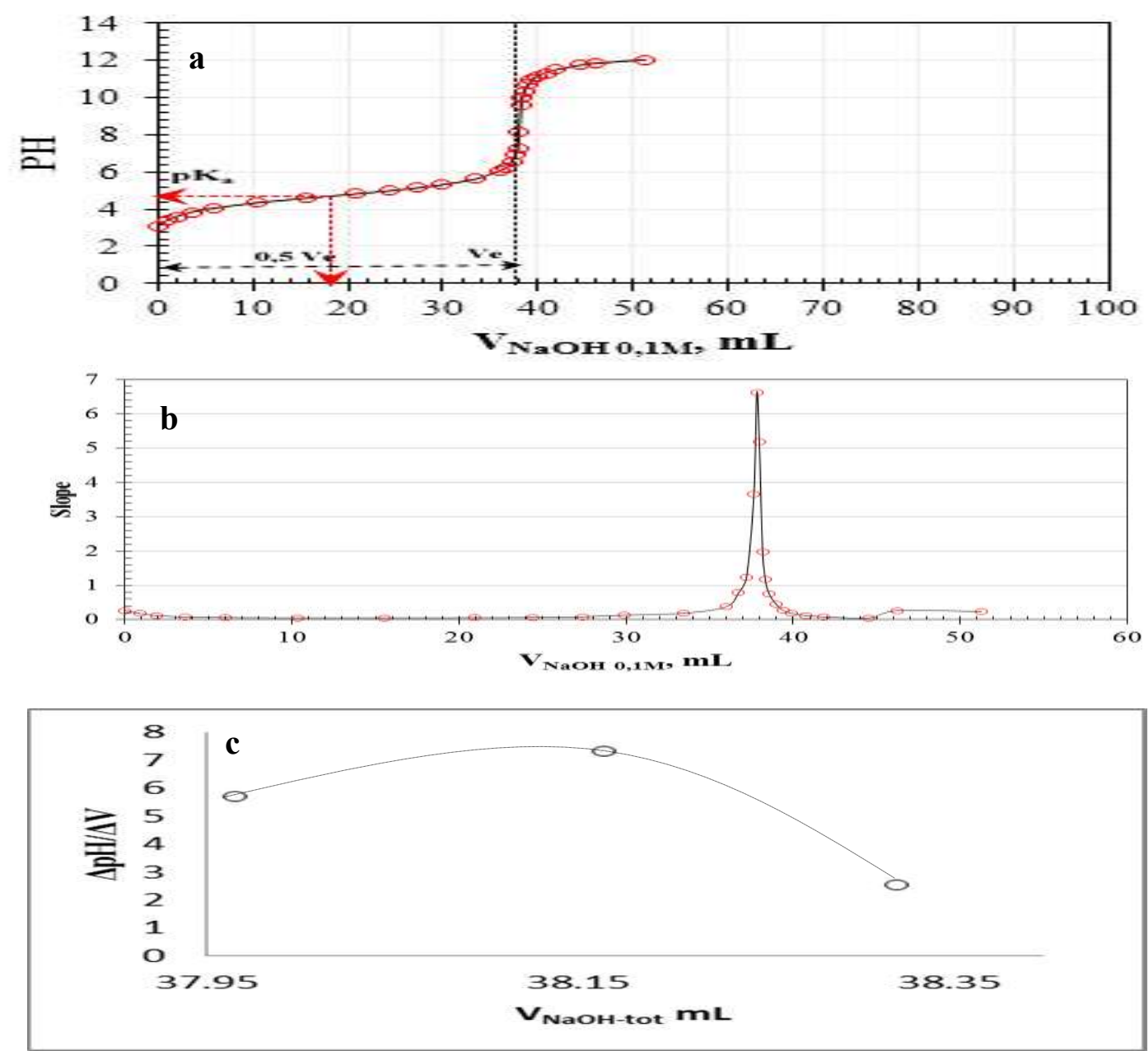

Gambar 3. Hubungan Antara Slope $(\Delta \mathrm{pH} / \Delta \mathrm{V})$ Dengan Volume NaOH 0,1M.

Dari gambar 3 terlihat bahwa titik ekuivalen titrasi asam asetat dengan $\mathrm{NaOH}$ $0,1 \mathrm{M}$ pada suhu $30^{\circ} \mathrm{C}$ dicapai pada saat volume penambahan $\mathrm{NaOH} 0,1 \mathrm{M}$ sebanyak $38,16 \mathrm{~mL}$. Volume ini disebut sebagai volume ekuivalen. Sedangkan nilai $\mathrm{pK}_{\mathrm{a}}$ dari asam asetat akan sama dengan $\mathrm{pH}$ larutan pada saat volume $\mathrm{NaOH} \quad 0,1 \mathrm{M}$ yang ditambahkan sebanyak setengah dari volume ekuivalen yaitu $19,08 \mathrm{~mL}$ dengan nilai $\mathrm{pK}_{\mathrm{a}}$ sebesar 4,751. Nilai $\mathrm{pK}_{\mathrm{a}}$ yang diperoleh pada percobaan ini mendekati nilai $\mathrm{pK}_{\mathrm{a}}$ asam asetat dari literatur yaitu 4,757 dengan deviasi $0,13 \%$.

Dengan metode dan alat percobaan yang sama, nilai $\mathrm{pK}_{\mathrm{a}}$ dari asam asetat untuk suhu yang lain dapat dilihat pada tabel 2 diatas.
Jika dilihat pada tabel 2 semakin tinggi suhu semakin tinggi nilai $\mathrm{pK}_{\mathrm{a}}$. Pada umumnya jika suhu dinaikkan, laju reaksi bertambah cepat dan nilai $\mathrm{pK}_{\mathrm{a}}$ asam juga semakin besar. Hal ini disebabkan semakin tinggi suhu maka kecepatan gerak partikel partikel pereaksi dan energi kinetik partikel akan meningkat. Dengan demikian, konstanta kesetimbangan asam asetat sebagai fungsi suhu dapat didekati dengan persamaan Arrhenius. Hubungan antara $-\ln \mathrm{K}_{\mathrm{a}}$ dengan 1/T dapat dilihat pada gambar 4. Dari gambar menunjukkan bahwa kurva $-\ln \mathrm{K}$ vs $1 / \mathrm{T}$ menghasilkan garis lurus pada hampir semua kasus. Maka, dari percobaan dan pengolahan data yang telah dilakukan dapat disimpulkan bahwa metode dan alat percobaan yang digunakan untuk pengukuran kesetimbangan asam $\left(\mathrm{pK}_{\mathrm{a}}\right)$ suatu senyawa dapat digunakan dengan baik dan menghasilkan nilai yang cukup baik. 


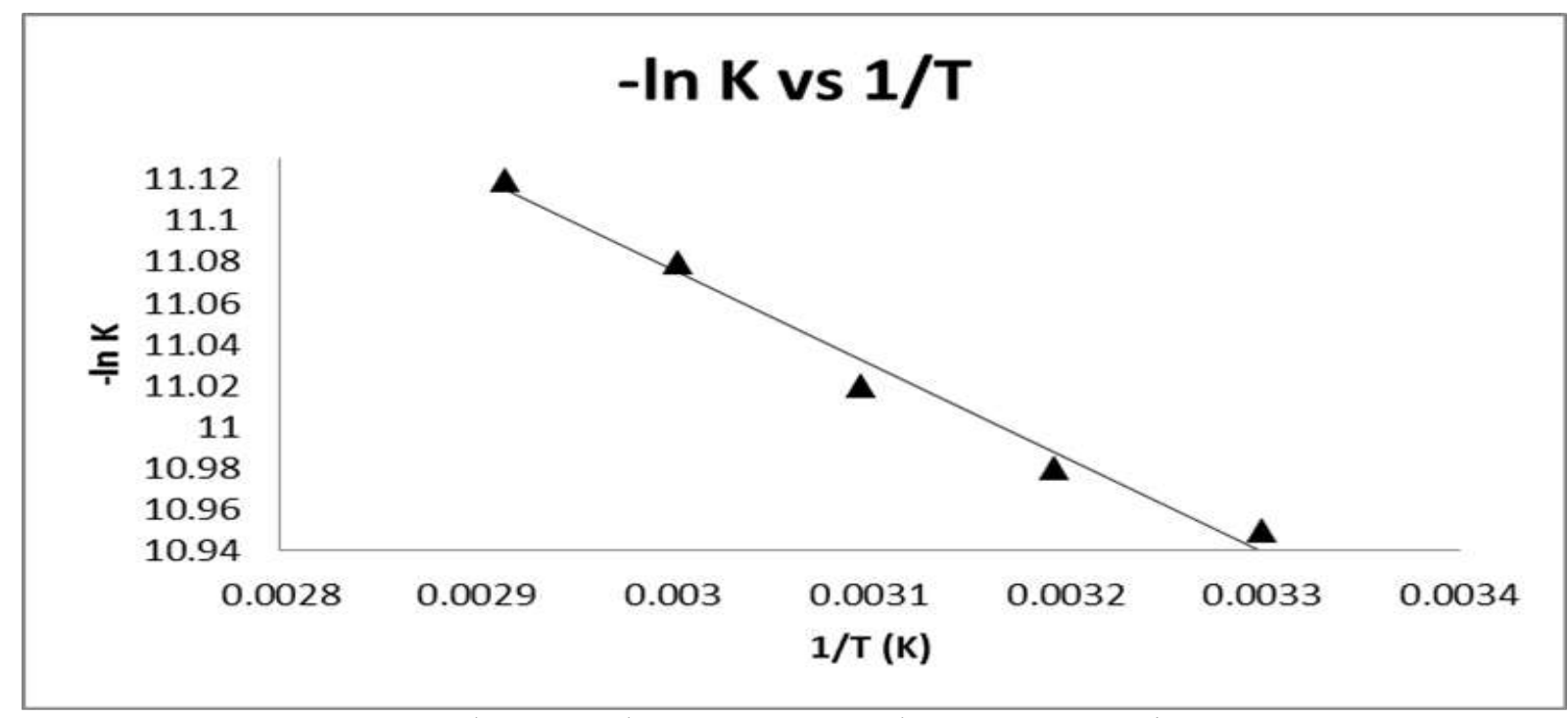

Gambar 4. Hubungan Antara - $\ln \mathrm{K}_{\mathrm{a}}$ Dengan 1/T.

\section{KESIMPULAN}

Berdasarkan hasil validasi pengukuran konstanta disosiasi asam asetat pada suhu 30$70^{\circ}$, maka dapat disimpulkan bahwa alat pengukur konstanta disosiasi asam yang telah dibuat layak untuk digunakan dalam penentuan nilai $\mathrm{pKa}$ pada suhu sampai dengan $70^{\circ} \mathrm{C}$. Selain itu, dari data percobaan terlihat bahwa semakin tinggi suhu percobaan maka semakin besar nilai $\mathrm{pK}_{\mathrm{a}}$.

\section{Ucapan Terima Kasih}

Peneliti mengucapkan terima kasih kepada Jurusan Teknik Kimia, Fakultas Teknologi Industri, Universitas Islam Indonesia, Yogyakarta, atas pendanaan penelitian ini melalui skema Penelitian Dosen dan Mahasiswa TA 2015/2016.

\section{DAFTAR PUSTAKA}

Alley, R. Climate Change: The Physical Science Basis. Contribution of Working Group I to the Fourth Assessment Report of the Intergovernmental Panel on Climate Change., 2007.

Harned, H. S., Ehlers, R. W., 1933. The dissociation of acetic acid from 0 to $60^{\circ}$ centigrade. J. Am. Chem. Soc. 55 652656.

Ma'mun, S., Svendsen, H. F, Hoff, K. A., Juliussen, O., 2007. Selection of new absorbents for carbon dioxide capture. Energy Convers. Manage., 48, 251-258.

NASA. Global Warming to Cause More Severe Tornadoes, Storms. Fox News, August 31, 2007.

Williams, M. Climate change: Information kit (Geneva: the United Nations Environment Programme and the United Nations Framework Convention on Climate Change), 2002. 